\title{
ARTIKELEN
}

\section{Excuses gemaakt, zand erover?}

\section{Over de perceptie van emotionele slachtoffers en de verwachte effecten van aangeboden excuses ${ }^{*}$}

Alice Bosma

\section{Slachtofferschap en herstel}

Slachtofferschap ontstaat op het moment dat iemand buiten zijn schuld nadeel lijdt. Slachtofferschap kan zich in velerlei contexten uiten, maar in deze bijdrage richt ik me op de context die meestal bedoeld wordt wanneer we het hebben over slachtofferschap: de context van misdrijven. Slachtofferschap door een misdrijf kenmerkt zich door het samenvallen van een harm: het leed dat wordt ervaren, en een wrong: het leed is aangedaan door een onrechtmatige actie van een ander (Duff, 2001; Pemberton, 2014). Wie slachtofferschap en herstel daarvan bestudeert, moet dus minimaal kijken naar de dynamiek tussen slachtoffer en dader op het moment van het ontstaan van het slachtofferschap. Omdat slachtofferschap een sociaal construct is (Dunn, 2008), is het echter van belang om nog wat breder te kijken: zowel interacties achteraf als interacties met derden die kennisnemen van de interactie tussen slachtoffer en dader mengen zich in de vraag wanneer iemand slachtoffer is en wanneer niet (meer).

In deze bijdrage wil ik laten zien dat ook in de fase van herstel de mening van de onafhankelijke individuele 'derde' die om wat voor reden dan ook - als vriend, familielid, kennis, voorbijganger, enzovoort - kennisneemt van het slachtofferschap en de poging tot herstel, niet moet worden vergeten. Door middel van een exploratieve experimentele studie laat ik zien dat de mening van de derde over het slachtoffer kan veranderen op basis van interactie tussen het slachtoffer en de dader, meer specifiek in reactie op het lezen van een verontschuldiging. Ik suggereer dat dat komt omdat de derde verwacht dat er herstel heeft plaatsgevonden, waardoor de derde tevens verwacht dat het slachtoffer zijn of haar houding zal aanpassen.

Daartoe zal ik eerst het begin en het einde van slachtofferschap helderder in kaart proberen te brengen en laten zien hoe de constructie van slachtofferschap altijd afhankelijk is van de verhouding tot anderen. In het bijzonder besteed ik aandacht aan verontschuldigingen. Daarna bespreek ik de empirische studie en ik sluit af met een discussie.

\footnotetext{
* $\quad$ Dataverzameling voor dit onderzoeksproject werd mede mogelijk gemaakt door beurs 17.01.03
} van Fonds Slachtofferhulp. 


\section{Het begin en het einde van slachtofferschap}

In artikel 51a Wetboek van Strafvordering ligt besloten dat eenieder die als rechtstreeks gevolg van een strafbaar feit nadeel heeft ondervonden, wordt aangemerkt als slachtoffer. Het begin van slachtofferschap is daarmee helder afgebakend. Andere juridische instrumenten, bijvoorbeeld de zogenoemde Slachtofferrichtlijn (Richtlijn 2012/29/EU), kennen vergelijkbare startpunten van slachtofferschap. Het einde van slachtofferschap wordt echter nergens gemarkeerd.

Het blijkt inderdaad lastig precies aan te geven waaruit het einde van slachtofferschap zou moeten bestaan. Zoals gezegd bestaat slachtofferschap door misdaad wanneer een harm en een wrong samengaan. Dat komt overeen met de zojuist genoemde juridische definitie die bestaat uit leed en daderschap van een strafbaar feit. Waar het leed voortduurt totdat herstel is gerealiseerd (bijvoorbeeld door schadevergoeding, psychische hulpverlening of anderszins), is de verantwoordelijkheid van de dader gesitueerd op één moment, namelijk in het ontstaan van het slachtofferschap. Het is voorstelbaar dat herstel gezien kan worden in een breed palet van genoegdoening, variërend van vergeving tot retributie. Op zijn minst is duidelijk dat waar bij het ontstaan van slachtofferschap door een misdrijf een harm en een wrong samenkomen, dat bij herstel de afname van deze constructen niet gelijk hoeft te lopen.

Met de inmiddels breed geaccepteerde conclusie dat slachtoffers vanaf het begin van hun slachtofferschap in verschillende mate herstellen en verschillende behoeften hebben (Laxminarayan, 2012; Lens, Pemberton \& Bogaerts, 2013) kunnen we, gezien bovenstaande, ook aannemen dat herstel verschillende betekenissen heeft voor verschillende slachtoffers en dat herstel in verschillende mate haalbaar is voor verschillende slachtoffers.

Toch heeft het begrip closure een centrale rol in de motivatie voor de wetgever om slachtofferrechten te creëren (Lens, Pemberton \& Groenhuijsen, 2010; Pemberton \& Reynaers, 2011) en herstelrechtelijke initiatieven te ontplooien. De term is door de jaren heen in verband gebracht met het ontvangen van antwoord op opengelaten vragen (bijvoorbeeld 'waarom ik?'), het loslaten van negatieve emoties en het bereiken van een gevoel dat dingen 'rechtgezet en/of geaccepteerd' zijn (Bandes, te verschijnen).

Eerder empirisch onderzoek dat ik elders uitgebreider besprek (Bosma, Groenhuijsen \& De Vries, 2020) suggereert dat het publiek over het algemeen verwacht dat een strafrechtelijke procedure en tenuitvoerlegging van een opgelegde straf het herstel bevorderen. In deze studie vroegen we onder andere in hoeverre men het idee had dat een persoon die nadeel had ondervonden als gevolg van een strafbaar feit daadwerkelijk aangemerkt kon worden als slachtoffer tijdens en na het strafproces. Er is een scherpe daling waarneembaar in de mate waarin men de benadeelde als slachtoffer ziet wanneer de tenuitvoerlegging van de sanctie ophoudt. Met andere woorden: door het eindigen van het strafrechtelijk traject waarin de wrong centraal staat, eindigt ook het slachtofferschap in zekere zin.

Ik veronderstel dat derden gelijksoortige verwachtingen hebben over het verminderen of eindigen van slachtofferschap wanneer zij vernemen dat alternatieve wegen zijn doorlopen om de wrong aan de orde te stellen. In deze bijdrage richt ik 
mij op verontschuldigingen. In de literatuur is wel vastgesteld dat een excuus kan helpen de relatie tussen het slachtoffer en de dader te herstellen (Allan, Beesley, Attwood \& McKillop, 2014; Dhami, 2012). Ook zou een excuus kunnen helpen negatieve emoties aan de kant van het slachtoffer te verminderen (Winkel, Schweizer, \& Pemberton 2010). Met andere woorden: men zou ervan uit kunnen gaan dat een verontschuldiging ervoor zorgt dat de beleving van slachtofferschap afzwakt.

\section{Slachtofferschap en de verhouding tot anderen}

Alvorens de hypothesen van de huidige studie te bespreken is het van belang aandacht te schenken aan de manier waarop derden slachtofferschap begrijpen. Het perspectief van het sociaal construct is hierbij behulpzaam. We gaan er dan van uit dat slachtofferschap een begrip is dat afhankelijk is van interpretatie. Slachtofferschap is daarmee geen objectieve omstandigheid, maar een subjectief label, een veranderlijke status (Daly, 2014). Dunn (2008) beschrijft dat slachtoffers het bijbehorende label kunnen 'claimen' bij anderen door middel van een 'collaboratief proces' waarbij het slachtoffer zich als zodanig presenteert en daardoor als zodanig begrepen kan worden. Hoe duidelijker het slachtoffer voldoet aan een duidelijk plaatje, hoe gemakkelijker het voor de derde is het slachtoffer ook daadwerkelijk te herkennen. Slechts wanneer de claim op het label als legitiem wordt ervaren (het plaatje wordt herkend) kan er een positieve verstandhouding tussen het slachtoffer en de derde ontstaan. Het slachtoffer wordt dan geloofwaardig geacht en maakt aanspraak op hulp. Wanneer er een mismatch is tussen de claim en de herkenning kan de perceptie van het slachtoffer juist negatief uitvallen: de derde vindt dat het slachtoffer overdrijft, geen/minder hulp verdient, enzovoort. Denk hierbij aan een slachtoffer van arbeidsuitbuiting: een gespierde Poolse arbeider die te weinig loon krijgt. Waarschijnlijk is hij moeilijker als slachtoffer te herkennen dan een fragiel meisje dat slachtoffer is van seksuele uitbuiting.

De theorie van het 'ideale slachtoffer' (Christie, 1986) kan vervolgens het te herkennen 'plaatje' duidelijk inkleuren. Christie beschrijft daartoe karakteristieken van het slachtoffer (zwak, respectabel, onschuldig) en van de dader (sterk, kwaadaardig) ten tijde van het ontstaan van slachtofferschap alsmede de relatie tussen slachtoffer en dader (onbekenden van elkaar). Een situatie die voldoet aan deze karakteristieken kan door een derde gemakkelijk worden begrepen als een omstandigheid waarin slachtofferschap is ontstaan. Sinds de eerste publicatie van The Ideal Victim is het plaatje uitgediept en bijgeschaafd (zie bijvoorbeeld Duggan, 2018). Met collega's heb ik eerder laten zien dat herkenning van het ideale slachtoffer niet alleen afhangt van de karakteristieken van slachtoffer, dader en hun onderlinge relatie ten tijde van het ontstaan van slachtofferschap, maar ook van gedragingen post-slachtofferschap (bijvoorbeeld het doen van aangifte) en de intrinsieke motivatie van de derde (Bosma, Mulder \& Pemberton, 2018).

Het uiten van emotie is een belangrijke post-slachtofferschap gedraging. Communicatie door middel van emoties kan de derde belangrijke informatie verschaffen (Van Kleef, 2016) die nodig is om de claim van slachtofferschap te beoordelen. In 
deze bijdrage maak ik onderscheid tussen boosheid en verdriet. Beide emoties worden sterk in verband gebracht met de ervaring van onrecht (Kamans, Van Zomeren, Gordijn \& Postmes, 2014; Mikula, Scherer \& Athenstaedt, 1998; Smith \& Lazarus, 1993), maar ieder op eigen wijze. Verdriet richt zich op de eerder besproken harm, terwijl boosheid een reactie is op een causale evaluatie van het leed, en daarmee de wrong belicht (Nussbaum, 2016). Een ander veel onderzocht verschil tussen verdriet en boosheid is dat verdriet stereotypisch een emotie is die passiviteit uitdrukt, terwijl boosheid actiever is (Tiedens, 2001). Om deze reden zou de uiting van verdriet beter bij de klassieke karakteristieken van het ideale slachtoffer passen (Bosma, Mulder, Pemberton \& Vingerhoets, 2018). Met andere woorden: een plaatje met een verdrietig slachtoffer herkent men gemakkelijker als zodanig.

Of de emotionele uiting van het slachtoffer leidt tot een succesvolle claim op het slachtoffer-label en daarmee erkenning van slachtofferschap door de derde, houdt daarnaast ook verband met de intensiteit van de uiting van de emotie. Uit het Emotional Victim Effect (EVE) kan worden afgeleid dat het voor erkenning van slachtofferschap van belang is dat de intensiteit van de geuite emotie in overeenstemming is met de ernst van het slachtofferschap (Lens, Van Doorn, Pemberton \& Bogaerts, 2014). Wordt niet voldaan aan de verwachtte intensiteit van de emotie, dan kan dat tot een negatieve perceptie van het slachtoffer leiden (Wrede, 2015). Dat geldt zowel voor een emotie die te sterk is, als voor een emotie die te zwak is ten opzichte van de perceptie van de ernst van slachtofferschap (Lens e.a., 2014).

\section{Excuses gemaakt, zand erover?}

Uit bovenstaande paragrafen kunnen twee, voor de huidige studie belangrijke, verwachtingen worden gedestilleerd. Verontschuldigingen van de dader kunnen - mits oprecht (Petrucci, 2002) en 'volledig' (Vanfraechem, Bolivar \& Aertsen, 2013, zie ook Bippus \& Young, 2019) - herstel van het slachtoffer van een misdrijf bevorderen en daarmee bijdragen aan het in zicht brengen van het einde van slachtofferschap. Of dit daadwerkelijk het geval is, hangt af van de omstandigheden van het geval en kan ook verschillend begrepen worden door de partijen die betrokken zijn bij de verontschuldiging (Petrucci, 2017). Ik verwacht dat een derde in elk geval de geboden verontschuldiging kan interpreteren als (een begin van) herstel. Ten tweede verwacht ik dat wanneer de derde ervan uitgaat dat het slachtoffer (deels) hersteld is, de derde ervan uit zal gaan dat de intensiteit van emotionele uiting van slachtofferschap door het slachtoffer proportioneel zal afnemen. Indien de intensiteit van de emotionele uiting niet afneemt, verwacht ik in lijn met EVE, dat de perceptie van het slachtoffer minder positief zal zijn. Deze verwachting ligt aan de basis van de huidige exploratieve experimentele studie. Daarnaast is ruimte voor de toets van twee hypothesen gebaseerd op de literatuur rond de emotie en excuses. Dit leidt tot de volgende set hypothesen: 
1 Een boos slachtoffer wordt door een derde minder positief gewaardeerd dan een verdrietig slachtoffer (gebaseerd op Bosma, Mulder, Pemberton e.a., 2018).

2 Een slachtoffer wordt door een derde minder positief gewaardeerd na het lezen van een verontschuldiging door de dader zo lang de emotionele uiting van het slachtoffer niet is aangepast.

3 De derde ervaart zelf minder boosheid na het lezen van een verontschuldiging door de dader (gebaseerd op Tsoudis \& Smith-Lovin, 1998)).

\section{Methoden}

In een experimentele vignettenstudie lazen participanten een slachtofferverklaring van een slachtoffer van een verkeersongeval veroorzaakt door een bestuurder die was afgeleid door het gebruik van een mobiele telefoon tijdens het rijden. Het slachtoffer, nog herstellende van zwaar lichamelijk letsel, vertelt in de verklaring ook mentaal ernstig aangedaan te zijn. In de ene conditie bestaat dat voornamelijk uit verdriet over het letsel, in de andere conditie bestaat dit uit boosheid over de veroorzaking van het letsel door de verdachte. De verdachte reageert op de verklaring door middel van een excuus.

\section{Participanten}

Participanten $(N=200)$ namen deel aan de Engelstalige studie via onderzoeksplatform Prolific Academic (Peer, Brandimarte, Samat \& Acquisti, 2017) en ontvingen daarvoor een vergoeding van $£ 1,50$. De leeftijd van participanten liep uiteen van 18 tot $80(M=35.52, S D=11.93)$ en $61 \%$ van de deelnemers aan de steekproef was vrouw. Participanten werden willekeurig ingedeeld in een van de twee condities (boze $(N=104)$ vs. verdrietige $(N=96)$ slachtofferverklaring).

\section{Procedure}

Participanten in zowel de verdrietige als de boze conditie kregen de schriftelijke versie van een gesproken slachtofferverklaring voor ogen. Beide versies bestonden uit een algemeen deel waarin de toedracht van het verkeersongeval werd beschreven en een gemanipuleerd deel waarin de emotionele gevolgen van het slachtofferschap werden beschreven. Na het lezen van de verklaring vulden participanten een eerste vragenlijst in over eigen ervaren emoties en perceptie van slachtoffer en verdachte. $\mathrm{Na}$ het invullen van de eerste vragenlijst lazen de deelnemers een tweede deel van het vignet, namelijk het deel waarin de verdachte uitgebreid zijn excuses aanbiedt. De excuses bestaan uit een zogenoemde 'volledige verontschuldiging' (Vanfraechem e.a., 2013). Hierna vulden participanten een tweede vragenlijst in, die grotendeels overeenkwam met de eerste vragenlijst, zodat er een voor- en nameting kon worden gedaan ten opzichte van het lezen van de verontschuldiging. 


\section{Variabelen $^{1}$}

Alle variabelen bestonden uit 6-punts Likertschaal waarbij 1 staat voor 'helemaal niet' en 6 voor 'heel erg'.

Manipulatiecheck. Ten behoeve van de manipulatiecheck werd in de eerste vragenlijst gevraagd in hoeverre men het slachtoffer boos en verdrietig vond overkomen en in de vragenlijst op meetmoment 2 in hoeverre men de verontschuldiging van de dader oprecht vond.

Eigen emotie. De eigen ervaren emotie werd op twee meetmomenten getoetst door te vragen in hoeverre participanten boosheid en verdriet voelden na het lezen van de slachtofferverklaring en de verontschuldiging.

Perceptie van het slachtoffer. De perceptie van het slachtoffer werd zowel gemeten na het lezen van de slachtofferverklaring als na het lezen van de verontschuldiging. Specifiek werd gevraagd naar hoe graag men het slachtoffer te hulp wilde schieten en in hoeverre men het eens was met de stelling dat het slachtoffer het volgende is/heeft: oprecht, geloofwaardig, een plezierig karakter, intelligent, een aangenaam persoon. De schaal vertoont een goede betrouwbaarheid op zowel meetmoment 1 (Cronbach's $\alpha=.83$ ) en meetmoment 2 (Cronbach's $\alpha=.88$ ).

\section{Resultaten}

\section{Manipulatiecheck}

Deelnemers die de boze slachtofferverklaring lazen, vonden het slachtoffer inderdaad bozer $(M=5.58, S D=.75)$ dan participanten in de conditie waarin een verdrietige slachtofferverklaring werd gelezen $(M=3.73, S D=1.39 ; t(139.33)=$ $-11.48, p<.001)$. In de verdriet-conditie vonden deelnemers de slachtofferverklaring ook verdrietiger $(M=5.76, S D=.56)$ dan in de boosheid-conditie $(M=4.64$, $S D=1.11 ; t(159.10)=9.07, p<.001)$. Het verschil in de emotionele toon van de slachtofferverklaring is dus begrepen door respondenten. Daarnaast blijkt dat ook de verontschuldiging onafhankelijk van de conditie goed is begrepen door respondenten $(\mathrm{M}=4.84, S D=1.11)$.

\section{Percepties van het slachtoffer}

Om hypothese 1 en hypothese 2 te testen heb ik een mixed ANOVA uitgevoerd op de perceptie van het slachtoffer, met meetmoment als within-subjects factor en conditie als between-subjects factor, zie figuur 1. In de steekproef gaven participanten een minder positief oordeel over boze $(M=4.63, S D=0.70)$ dan verdrietige slachtoffers $(M=4.79, S D=0.83)$ direct na het lezen van de slachtofferverklaring. Het verschil is vergelijkbaar na het lezen van de verontschuldiging $\mathrm{M}_{\text {boos }}=$ $4.42, S D=0.83 ; M_{\text {verdrietig }}=4.64, S D=0.87$ ). De richting van het hoofdeffect van emotie is hiermee in lijn met de eerste hypothese, maar niet statistisch significant, $F(1,198)=3.21, p=.075, d=0.25$. Het afwezige interactie-effect tussen

1 De experimentele setting werd gebruikt voor een groter project. In deze bijdrage worden slechts de variabelen besproken die relevant zijn voor de huidige studie. 


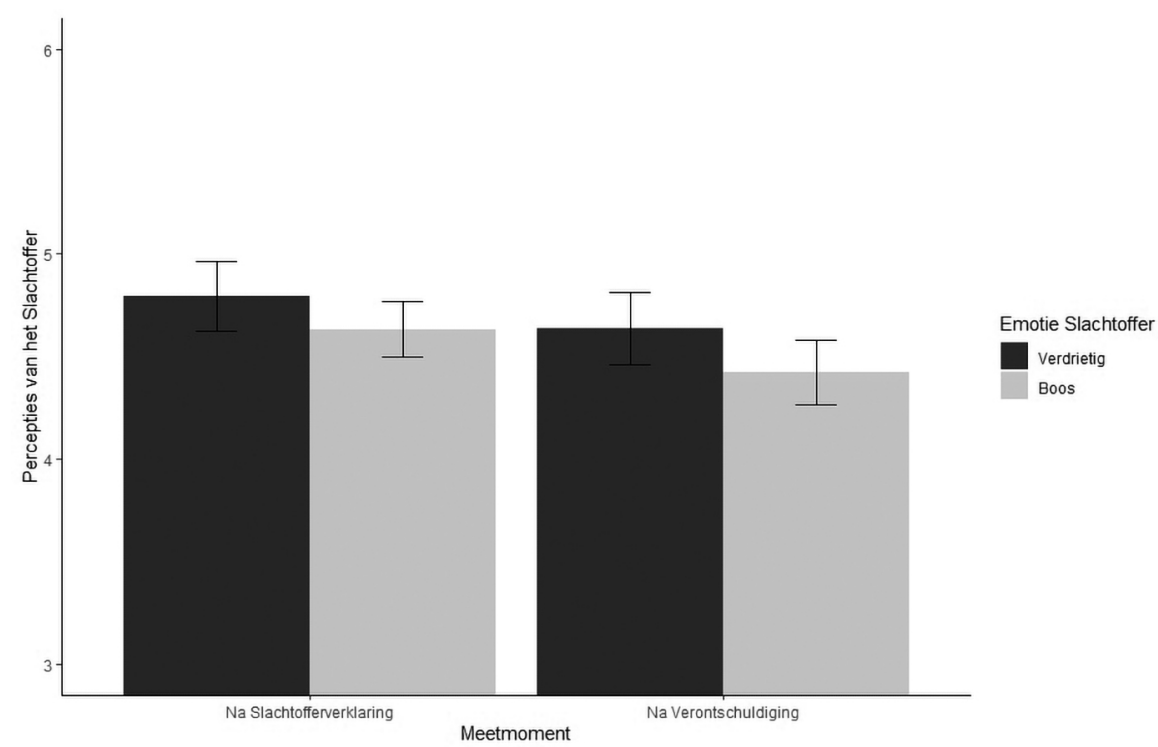

Figuur 1 Percepties van boze en verdrietige slachtoffers voor en na een verontschuldiging

meetmoment en emotionele toon van de slachtofferverklaring laat zien dat dit effect hetzelfde is voor beide metingen, $F(1,198)=0.37, p=.55, \eta p^{2}=0.002$.

In lijn met hypothese 2 vonden we een hoofdeffect van het meetmoment. Participanten beoordeelden het slachtoffer als minder positief (maar nog steeds boven het mid-punt van de schaal) na het lezen van de verontschuldiging $(M=4.52, S D$ $=0.85)$ dan voor het lezen van dit excuus $(M=4.71, S D=0.77), F(1,198)=16.51$, $p<.001, d=0.23$.

Eigen emotie van de derde

Om hypothese 3 te testen heb ik een within-subject ANOVA uitgevoerd op de ervaren emoties met als factoren type emotie (boosheid en verdriet) en meetmoment, zie figuur 2. Het hoofdeffect van meetmoment toont een afname in ervaren emoties, $F(1,199)=165.39, p<.001, \eta p^{2}=0.45$. Ook vond ik een interactie-effect tussen emotie en meetmoment, $F(1,199)=5.74, p=.02, \eta p^{2}=0.03$. Simple main effects met Bonferroni-correctie, tonen het volgende aan. Ervaren boosheid op meetmoment $2(M=2.75, S D=1.46)$ is lager dan op meetmoment $1(M=3.61$, $S D=1.20), p<.001, d=0.64$. Ervaren verdriet is op meetmoment $2(M=3.43, S D$ = 1.40) ook lager dan op meetmoment $1(M=4.64, S D=1.31), p<.001, d=0.89$. In beide gevallen is er dus een afname in de ervaren emotie, maar deze afname lijkt sterker voor verdriet dan voor boosheid. Tevens vinden we een hoofdeffect van ervaren emotie: participanten ervaren meer verdriet $(M=4.04, S D=1.09)$ dan boosheid $(M=3.18, S D=1.11), F(1,199)=120.59, p<.001, d=0.78$. 


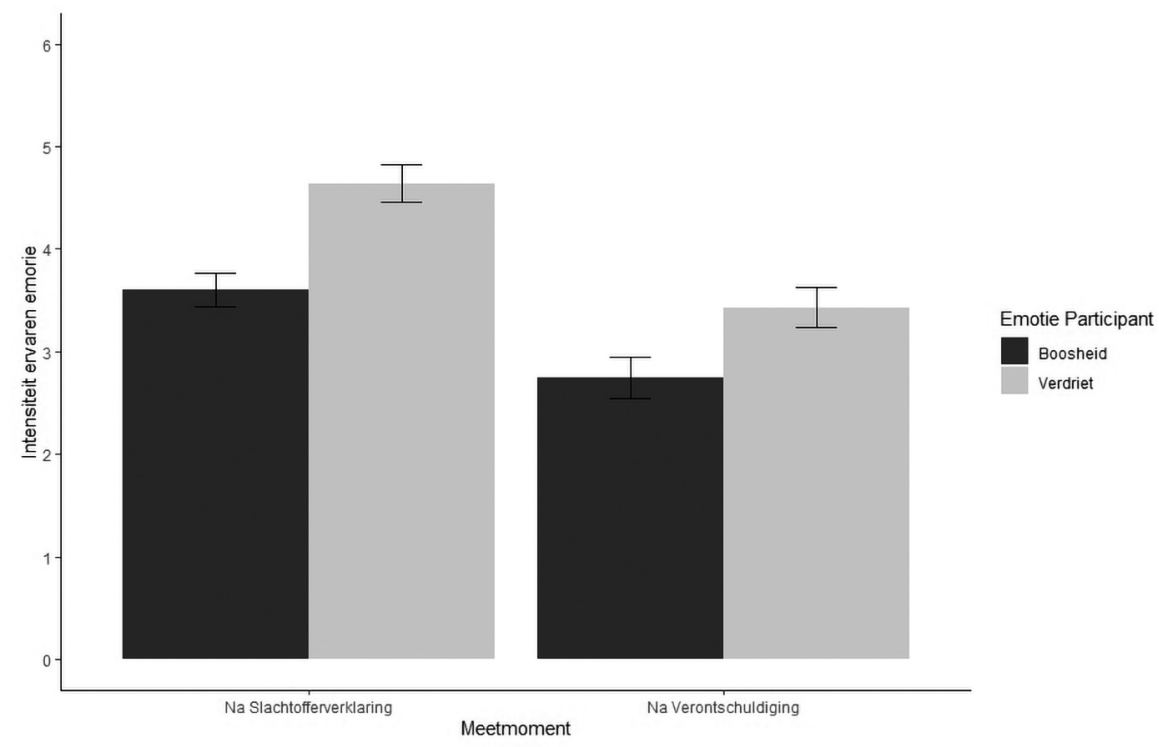

Figuur 2 Ervaren boosheid en verdriet door participanten voor en na een verontschuldiging

\section{Discussie}

De perceptie van boze versus verdrietige slachtoffers

In eerdere studies hebben collega's en ik gevonden dat een boos slachtoffer minder positief wordt beoordeeld dan een verdrietig slachtoffer (Bosma, 2019; Bosma, Mulder, Pemberton e.a., 2018). Die bevinding hebben we gekoppeld aan het verbreken van een stereotype: het slachtoffer wordt volgens de theorie van het ideale slachtoffer steeds gekoppeld aan passiviteit en zwakte. Verdriet straalt datzelfde uit, terwijl boosheid kracht uitstraalt. Een boos slachtoffer past dus voor de observerende derde minder goed in het plaatje van het ideale slachtoffer (Christie, 1986; Bosma, 2019, Bosma, Mulder, Pemberton e.a., 2018). In de huidige studie vond ik op beide meetmomenten wel resultaten in de voorspelde richting, maar de verschillen waren niet significant. Een mogelijke reden voor het verschil met eerdere studies is dat in de huidige studie een ander type slachtofferschap centraal stond, namelijk slachtofferschap na een verkeersongeval. In eerdere studies keken we steeds naar fysiek geweld. Waar we keken naar seksueel geweld vonden we eveneens geen verschillen in de beoordeling van het boze en het verdrietige slachtoffer. De bredere context van slachtofferschap lijkt dus van belang voor de beoordeling van het type emotie dat wordt geuit door het slachtoffer.

\section{Eigen emotie van de derde}

De literatuur biedt aanknopingspunten voor het idee dat niet alleen de negatieve emoties van het slachtoffer kunnen afnemen op basis van een excuus van de 
dader, maar dat ook de observerende derde - die boos of verdrietig kan worden van het onrecht waarvan hij of zij kennisnam - afnemende negatieve emoties kan ondervinden op basis van een verontschuldiging van de dader. Tot nu toe is er met name veel aandacht besteed aan boosheid van de derde (Tsoudis \& SmithLovin, 1998). De huidige studie ondersteunt deze bevinding en voegt daaraan toe dat eenzelfde dynamiek is waar te nemen voor ervaren verdriet. De mate waarin deelnemers verdriet ervoeren nam zelfs sterker af dan de mate waarin hun boosheid afnam. In hoeverre de afname van eigen ervaren emotie de verwachting met betrekking tot herstel bij het slachtoffer beïnvloedt, heb ik in deze studie niet direct kunnen toetsen, maar is wel een onderwerp voor toekomstige bestudering.

\section{Percepties van het emotionele slachtoffer na de verontschuldiging}

De belangrijkste bijdrage van de huidige studie is dat de percepties van het slachtoffer veranderen wanneer een dader excuses heeft aangeboden en het slachtoffer zijn of haar uiting van slachtofferschap niet verandert. Ik heb dit ingebed in het Emotional Victim Effect: door de verontschuldiging zal de derde veronderstellen dat er een bepaalde mate van herstel zal plaatsvinden. Ten opzichte van de situatie voorafgaand aan de verontschuldiging is de beleving van het slachtofferschap afgezwakt. De derde verwacht dus dat de beleving slachtofferschap - in dit geval de uiting van een emotie die sterk gelieerd is aan de ervaring van onrecht - zal afnemen. Wanneer dit niet gebeurt, ontstaat er een mismatch tussen de intensiteit van de emotie en de intensiteit van het ervaren slachtofferschap. De claim op het slachtoffer-label wordt daardoor minder legitiem in de ogen van de derde, waardoor de evaluatie van het slachtoffer minder positief is.

De studie kent een aantal belangrijke beperkingen. Ten eerste voorzag het design niet in een reactie van het slachtoffer op de verontschuldiging. De ongewijzigde houding van het slachtoffer werd dus niet expliciet bevestigd. In toekomstig onderzoek kan er gevarieerd worden in de reactie van het slachtoffer, zowel in acceptatie van de verontschuldiging (wat herstel al dan niet bevestigt) en emotionele uiting. Ten tweede rust de bovengenoemde uitleg op een aantal assumpties die niet getest zijn: de verwachtingen van de deelnemers zijn niet expliciet uitgevraagd. Een schakel in de keten zou kunnen zijn dat derden minder medeleven of sympathie voelen richting het slachtoffer. Daarnaast is er weinig gevarieerd in de context van het slachtofferschap, terwijl deze wel van groot belang kan zijn. Wellicht leent het ene delict zich beter voor herstel of een volledige verontschuldiging dan het andere in de ogen van de derde. Tot slot zijn de verschillen tussen de meetmomenten significant, maar de effectgroottes zijn beperkt.

De studie was echter bedoeld als eerste exploratieve aanzet om te bekijken hoe de mening van de derde over het slachtoffer kan veranderen op basis van interactie tussen het slachtoffer en de dader. Dat is een breder onderwerp, waarvoor verschillende typen interactie bekeken zouden moeten worden. In vervolgstudies zal bekeken moeten worden wat er verandert als het slachtoffer zijn of haar emotionele uiting wijzigt naar aanleiding van de excuses. Dit zal moeten worden bekeken in verschillende contexten en op basis van verschillende vormen van strafrechtelijke en herstelrechtelijke initiatieven die de harm en de wrong van het slachtoffer (lijken) aan (te) pakken. 
Met deze bijdrage heb ik niet het belang van excuses (of enige andere vorm van herstelrechtelijke initiatieven) willen ontkennen. Slachtoffers kunnen hier, zoals meermaals aangetoond in de literatuur, wel degelijk baat bij hebben. Ik heb slechts willen wijzen op het belang een brede blik te houden en zich bewust te zijn van andere individuen om het slachtoffer en de dader heen. Iedere interactie tussen slachtoffer en dader is ook van invloed op hoe een derde het slachtoffer ziet en in hoeverre deze derde emoties zoals geuit door het slachtoffer als legitiem ervaart. Door dit beter in kaart te brengen kunnen we reacties van derden op het slachtoffer beter leren begrijpen. Een ervan is hier uitgebreid besproken. Derden verwachten dat het ontvangen van excuses betekent dat het ervaren slachtofferschap wordt beëindigd: zand erover, streep eronder.

\section{Literatuur}

Allan, A., S.M. Beesley, B. Attwood \& D. McKillop (2014) Apology in restorative and juvenile justice. Psychiatry, Psychology and Law, 21(2), 176-190. doi: 10.1080/13218719.2013.803274.

Bandes, S.A. (te verschijnen). Closure in the criminal courtroom. In: S.A. Bandes, J. Madeira, K. Temple \& E.K. White (red.), Research Handbook on Law and Emotion. Edward Elgar Publishing.

Bippus, A.M. \& S.L. Young (2019) How to say: 'I’m sorry:' Ideal apology elements for common interpersonal transgressions. Western Journal of Communication, 0(0), 1-15. doi: 10.1080/10570314.2019.1610787.

Bosma, A.K. (2019) Emotive Justice. Laypersons' and legal professionals' evaluation of emotional victims within the just world paradigm. Tilburg: Wolf Legal Publishers.

Bosma, A.K., M.S. Groenhuijsen \& G.M. de Vries (2020) De positie van het slachtoffer aan de voorkant van de executiefase. Delikt \& Delinkwent, 2020(7).

Bosma, A.K., E. Mulder \& A. Pemberton (2018) The ideal victim through other(s') eyes. In: M. Duggan (red.), Revisiting the 'Ideal Victim' (pp. 27-41). Bristol: Policy Press.

Bosma, A.K., E. Mulder, A. Pemberton \& A.J.J.M. Vingerhoets (2018) Observer reactions to emotional victims of serious crimes: Stereotypes and expectancy violations. Psychology, Crime \& Law, 1-21. doi:10.1080/1068316X.2018.1467910.

Christie, N. (1986) The ideal victim. In: E.A. Fattah (red.), From crime policy to victim policy (pp. 17-30). Basingstoke: Macmillan.

Daly, K. (2014) Reconceptualizing sexual vicitmizatin and justice. In: I. Vanfraechem, A. Pemberton \& F.M. Ndahinda (red.), Justice for victims (pp. 378-395). New York: Routledge.

Dhami, M.K. (2012) Offer and acceptance of apology in victim-offender mediation. Critical Criminology, 20(1), 45-60. doi:10.1007/s10612-011-9149-5.

Duff, R.A. (2001) Harms and wrongs. Buffalo Criminal Law Review, 5(1), 13-45.

Duggan, M. (2018) Revisiting the 'Ideal Victim'. Developments in critical victimology. Bristol: Policy Press.

Dunn, J.L. (2008) Accounting for victimization: Social constructionist perspectives. Sociology Compass, 2(5), 1601-1620. doi:10.1111/j.1751-9020.2008.00150.x.

Kamans, E., M. van Zomeren, E.H. Gordijn \& T. Postmes (2014) Communicating the right emotion makes violence seem less wrong: Power-congruent emotions lead outsiders to legitimize violence of powerless and powerful groups in intractable conflict. Group Processes \& Intergroup Relations, 17(3), 286-305. doi:10.1177/1368430213502562. 
Kleef, G.A. van (2016) The interpersonal dynamics of emotion: toward an integrative theory of emotions as social information. Cambridge: Cambridge University Press.

Laxminarayan, M.S. (2012) The heterogeneity of crime victims: Variations in procedural and outcome preferences. Nijmegen: Wolf Legal Publishers.

Lens, K.M.E., A. Pemberton \& S. Bogaerts (2013) Heterogeneity in victim participation: A new perspective on delivering a victim impact statement. European Journal of Criminology, 10(4), 479-495. doi:10.1177/1477370812469859.

Lens, K.M.E., A. Pemberton \& M.S. Groenhuijsen (2010) Het spreekrecht in Nederland: Een bijdrage aan het emotioneel herstel van slachtoffers?. Tilburg: INTERVICT.

Lens, K.M.E., J. van Doorn, A. Pemberton \& S. Bogaerts (2014) You shouldn't feel that way! Extending the emotional victim effect through the mediating role of expectancy violation. Psychology, Crime and Law, 20(4), 326-338. doi:10.1080/1068316X. 2013.777962.

Mikula, G., K.R. Scherer \& U. Athenstaedt (1998) The role of injustice in the elicitation of differential emotional reactions. Personality \& social psychology bulletin, 24(7), 769-783. doi:10.1177/0146167298247009.

Nussbaum, M.C. (2016) Anger and forgiveness: resentment, generosity, justice. New York: Oxford University Press.

Peer, E., L. Brandimarte, S. Samat \& A. Acquisti (2017) Beyond the turk: Alternative platforms for crowdsourcing behavioral research. Journal of Experimental Social Psychology, 70, 153-163. doi:10.1016/j.jesp.2017.01.006.

Pemberton, A. (2014) Respecting victims of crime. Key distinctions in a theory of victims' rights. In: I. Vanfraechem, A. Pemberton \& F.M. Ndahinda (red.), Justice for victims (pp. 32-50). New York: Routledge.

Pemberton, A. \& S. Reynaers (2011) The controversial nature of victim participation: Therapeutic benefits in victim impact statements. In: E. Erez, M. Kilchlinh \& J.M. Wemmers (red.), Therapeutic jurisprudence and victim participation in justice: International perspectives (pp. 229-248). Durnham: Carolina Academic Publishing.

Petrucci, C.J. (2002) Apology in the criminal justice setting: evidence for including apology as an additional component in the legal system. Behavioral Sciences \& the Law, 20(4), 337-362. doi:10.1002/bsl.495.

Petrucci, C.J. (2017) Apology in the criminal justice setting: An update. Onati Socio-Legal Series, 7(3), 437-454.

Smith, C. \& R. Lazarus (1993) Appraisal components, core relational themes, and the emotions. Cognition \& Emotion, 7(3-4), 233-269. doi:10.1080/02699939308409189.

Tiedens, L.Z. (2001) Anger and advancement versus sadness and subjugation: The effect of negative emotion expressions on social status conferral. Journal of personality and social psychology, 80(1), 86-94. doi:10.1037//0022-3514.80.1.86.

Tsoudis, O. \& L. Smith-Lovin (1998) How bad was it? The effects of victim and perpetrator emotion on responses to criminal court vignettes. Social Forces, 77(2), 695. doi: $10.2307 / 3005544$.

Vanfraechem, I., D. Bolivar \& I. Aertsen (2013) The ritual of apology and restorative justice: The victim's perspective. In: D. Cuypers, D. Janssen, J. Haers \& B. Segaert (red.), Public apology between ritual and regret (pp. 123-144). Amsterdam/New York: Rodopi.

Winkel, F.W., K. Schweizer \& A. Pemberton (2010) Victim-offender dialogue: an analogue study examining the impact of apology on anger. Acta Criminologica, 23(1), 1-13.

Wrede, O. (2015) The role of emotions in judgments of crime victims. University of Gothenburg. beschikbaar op http://hdl.handle.net/2077/40837. 